\title{
The Relationship of Post-traumatic Stress Disorder to End-of-life Care Received by Dying Veterans: a Secondary Data Analysis
}

\author{
Kathleen E. Bickel, MD, MPhil, MS ${ }^{1,2}$, Richard Kennedy, MD, PhD ${ }^{3}$, Cari Levy, MD, PhD ${ }^{2,1}$, \\ Kathryn L. Burgio, $P h D^{4,3}$, and F. Amos Bailey, $M D^{1,4}$
}

\begin{abstract}
'University of Colorado School of Medicine, Rocky Mountain VA Medical Center, Aurora, CO, USA; ${ }^{2}$ Rocky Mountain Veterans Affairs Medical Center, Aurora, USA; ${ }^{3}$ The University of Alabama at Birmingham, Birmingham, Alabama, USA; ${ }^{4}$ Birmingham Veterans Affairs Medical Center, Birmingham, Alabama, USA.
\end{abstract}

\begin{abstract}
BACKGROUND: Post-traumatic stress disorder (PTSD) can be exacerbated by subsequent trauma, but it is unclear if symptoms are worsened by impending death. PTSD symptoms, including hyperarousal, negative mood and thoughts, and traumatic re-experiencing, can impact end-of-life symptoms, including pain, mood, and poor sleep. Thus, increased symptoms may lead to increased end-of-life healthcare utilization.

OBJECTIVES: To determine if veterans with PTSD have increased end-of-life healthcare utilization or medication use and to examine predictors of medication administration. DESIGN: Secondary analysis of a stepped-wedge design implementation trial to improve end-of-life care for Veterans Affairs (VA) inpatients. Outcome variables were collected via direct chart review. Analyses included hierarchical, generalized estimating equation models, clustered by medical center. SUBJECTS: Veterans, inpatient at one of six VA facilities, dying between 2005 and 2011 .
\end{abstract}

MAIN MEASURES: Emergency room (ER) visits, hospitalizations, and medication administration in the last 7 days of life.

KEY RESULTS: Of 5341 veterans, 468 (8.76\%) had PTSD. Of those, $21.4 \%$ (100/468) had major depression and 36.5\% (171/468) had anxiety. Veterans with PTSD were younger (mean age 65.4 PTSD, 70.5 no PTSD, $p<0.0001$ ) and had more VA hospitalizations and ER visits in the last 12 months of life (admissions: PTSD 2.8, no PTSD 2.4, $p<0.0001$; ER visits: 3.2 vs $2.5, p<0.0001)$. PTSD was associated with antipsychotic administration (OR 1.52, 95\% CI 1.06-2.18). Major depression $(333 / 5341,6.2 \%)$ was associated with opioid administration (OR 1.348, 95\% CI 1.129-1.609) and benzodiazepines (OR 1.489, 95\% CI 1.141-1.943). Anxiety disorders $(778 / 5341,14.6 \%)$ were only associated with benzodiazepines (OR 1.598, 95\% CI 1.194-2.138).

CONCLUSIONS: PTSD's association with increased endof-life healthcare utilization and increased antipsychotic

Electronic supplementary material The online version of this article (https://doi.org/10.1007/s11606-019-05538-x) contains supplementary material which is available to authorized users

Prior Presentation Data from this paper was presented as an oral abstract at the 2019 Annual Assembly of the American Academy of Hospice and Palliative Medicine. Orlando. EL. March 15.2019.

Received January 16, 2019

Revised August 6, 2019

Accepted October 18, 2019

Published online December 2, 2019 administration in the final days of life suggests increased symptom burden and potential for terminal delirium in individuals with PTSD. Understanding the burden of psychiatric illness and potential risks for delirium may facilitate the end-of-life care for these patients.

TRIAL REGISTRATION: NCT00234286

KEY WORDS: PTSD; end of life care; utilization; mental health; veterans.

J Gen Intern Med 35(2):505-13

DOI: $10.1007 /$ s11606-019-05538-x

(c) Society of General InternalMedicine (This is a U.S. government work and not under copyright protection in the U.S.; foreign copyright protection may apply) 2019

\section{INTRODUCTION}

Despite its inevitability, death is often considered a poor outcome in medicine and in society. Accepting a poor prognosis and navigating the last months of life can be challenging for anyone ${ }^{1}$ and is potentially harder for individuals predisposed to depression or anxiety. ${ }^{2}$

Generally, individuals with psychiatric illness have higher healthcare utilization, ${ }^{3-6}$ lower quality of life and functional status, ${ }^{7-10}$ and worse medical outcomes ${ }^{10,11}$ than the general population. Individuals with psychiatric illness may have difficulty coping with life stressors ${ }^{12}$ and are at risk for relapse or worsening symptoms during major life changes, such as retirement, divorce, or death. ${ }^{13,14}$ Individuals with post-traumatic stress disorder (PTSD) may be specifically at risk for relapse or worsening symptoms as their own death approaches because PTSD requires exposure to a trauma, specifically near death or threatened death. ${ }^{15}$ Due to the traumatic encoding of memories in PTSD, ${ }^{16}$ reminders of one's own death may consciously or unconsciously trigger reminders of prior trauma. Thus, in terminal illness, any reminders of impending death could be re-traumatizing or exacerbate the symptoms of patients with PTSD. However, the effects of PTSD on symptom burden and healthcare utilization in the last months of life have not been well studied.

Diagnostically, PTSD consists of four clusters, re-experiencing, avoidance, negative cognitions and mood, and increased arousal. ${ }^{15}$ PTSD frequently co-exists with other 
psychiatric illness, such as mood or substance use. ${ }^{17,}{ }^{18}$ PTSD also negatively affects pain sensation and interpretation, ${ }^{19-21}$ causes poor sleep, ${ }^{15}$ and can lead to somatization. ${ }^{22,}{ }^{23}$ PTSD's course can be chronically symptomatic, resolving over time, remitting and relapsing, or with late onset. ${ }^{24-29}$ Trajectories vary depending on trauma type, treatment, and other factors. ${ }^{25-27,30-}$

${ }^{32}$ Life stressors, such as retirement or death of loved ones, have been correlated with PTSD relapse or worsening symptoms. ${ }^{32-}$ ${ }^{36}$ Specifically, the theory of later-adulthood trauma reengagement describes later-life worsening of PTSD symptoms as a part of life reminiscence, which is triggered by common older life events, such as physical or cognitive decline, role transitions, or deaths of loved ones. ${ }^{37,}{ }^{38}$ However, it is unclear how often PTSD symptoms occur or if they impact medical care in the final months and days of life, as death nears.

United States (US) PTSD prevalence rates are 3.5\% current and $6.8 \%$ lifetime, but as low as $2.5 \%$ in the older population. ${ }^{39-42}$ Studies have quoted increased PTSD rates in various life-threatening medical conditions: $2.3-18 \%$ in cancer, ${ }^{43-45}$ $30-54 \%$ in human immunodeficiency virus (HIV), ${ }^{46,47}$ and in $3.7-59 \%$ of patients admitted to the intensive care unit (ICU). ${ }^{48-50}$ These rates vary, as different tools and time periods were used to diagnose PTSD. The gold standard for PTSD diagnosis is a structured clinical interview, and symptoms must persist for at least one month. ${ }^{15}$ PTSD rates are lower when using these criteria. ${ }^{45,48}$

PTSD is often studied within Veterans Affairs (VA), due to combat trauma exposure. VA is also the largest national healthcare system to routinely screen all patients for PTSD. ${ }^{51}$ Outside of VA, PTSD screening varies and is often under-diagnosed. ${ }^{52-}$ ${ }^{54}$ Therefore, to test our hypothesis that PTSD symptoms worsen at the end of life, manifested by increased healthcare utilization or increased medication use, we sought to study PTSD in VA. We conducted an exploratory, secondary analysis of data describing end-of-life care received by veterans, dying in VA medical centers from the Best Practices for End-of-Life Care for Our Nation's Veterans (BEACON) trial. ${ }^{55}$

\section{METHODS}

\section{Description of the Primary Study}

The BEACON study has been previously described.$^{55}$ It was a multisite, stepped-wedge implementation trial of a multicomponent intervention to improve the quality of end-of-life care in VA medical centers, including ensuring that routinely prescribed medications and comfort-focused practices were ordered for dying inpatients via implementation of a Comfort Care Order Set. Additional details in online Appendix 1 (online).

\section{BEACON Data Collection}

A standardized chart abstraction tool was used to record the primary terminal diagnosis of each veteran and the end-of-life care process outcomes in the last 7 days of life, including administration of opioids, benzodiazepines, or antipsychotics; presence of an intravenous line or nasogastric tube at the time of death; location of death; and record of an advanced directive or a do not resuscitate (DNR) order. Inter-rater reliabilities were established between the chart abstractor and the Director of Palliative Care at the coordinating center.

Demographic data, including race, and medical and psychiatric comorbidities were obtained from the VA National Data Sets in Austin, Texas. The first 15 comorbidities indicated by International Statistical Classification of Diseases, 9th edition (ICD-9) code in each veterans' electronic medical record problem list were included.

\section{Secondary Analysis}

Chi-square was used to compare categorical values and Student's $t$ test to compare continuous values between participants with and without PTSD. A Bonferroni correction was used to account for the multiple comparisons, yielding $\alpha=0.05 / 32=$ 0.0016 for the $p$ value for these comparisons only.

Primary outcomes were VA emergency room (ER) visits, admissions, and administration of each medication class (opioids, benzodiazepines, antipsychotics, and all three classes together). Models used generalized estimating equations (GEE) to account for the clustering of patients within sites ${ }^{56}$ and were adjusted to account for the small number of clusters. ${ }^{57-60}$ Poisson and logistic models were used for count (ER visits and VA admissions) and binary (administration of medication) data, respectively. Predictors were added hierarchically to examine potential moderating effects of each group of predictors. These predictors were (1) PTSD alone; (2) demographics (year of death, race, age, gender, intervention arm); (3) psychiatric comorbidities (anxiety disorders, any dementia diagnosis, major depression, alcohol use disorder, schizophrenia, non-nicotine drug use disorder); and (4) terminal diagnosis of cancer (no/yes). The categorical intervention variable denoted whether the patient died before or after the BEACON intervention ${ }^{55}$ was implemented at that VA facility to account for temporal trends from the primary intervention.

\section{RESULTS}

\section{Patient Characteristics}

Of the 5341 veterans included in this analysis, 1946 (36.4\%) had at least one psychiatric illness and $468(8.76 \%)$ had a diagnosis of PTSD (Appendix Table 5-online). Table 1 characterizes the demographic differences between veterans with and without PTSD. The cohort was predominantly male (98.2\%) and was 31.6\% African-American, reflecting the racial distribution of the participating VA medical centers. Veterans with PTSD were significantly younger at death than those without PTSD, with mean ages of 65.4 and 70.1, respectively $(p<0.0001)$. Psychiatric comorbidities were statistically more prevalent in veterans with PTSD, $36.5 \%$ with anxiety disorder and $21.4 \%$ with major depressive disorder. 
Table 1 Demographic Characteristics of 5341 Veterans in the BEACON Intervention Trial Who Died as Inpatients in One of 6 VA Medical Facilities, Stratified by PTSD Diagnosis

\begin{tabular}{|c|c|c|c|c|}
\hline \multirow[t]{2}{*}{$\overline{\text { Characteristics }}$} & \multicolumn{2}{|c|}{ PTSD diagnosis } & \multirow[t]{2}{*}{ Total $(n=5341)$} & \multirow[t]{2}{*}{ Chi-square, $p$ value } \\
\hline & Yes $(n=468)$ & No $(n=4873)$ & & \\
\hline Male gender & $462(98.7)$ & $4784(98.2)$ & $5246(98.2)$ & \multirow{5}{*}{$\begin{array}{l}0.39 \\
0.058\end{array}$} \\
\hline \multicolumn{4}{|l|}{ Race } & \\
\hline Black & $171(36.5)$ & $1519(31.2)$ & 1690 (31.6) & \\
\hline White & $261(55.8)$ & $2940(60.3)$ & $3201(59.9)$ & \\
\hline Other & $36(7.7)$ & $414(8.5)$ & $450(8.4)$ & \\
\hline Mean age at death in years (SD)* & $65.4(10.4)^{*}$ & $70.5(11.5)^{*}$ & $70.1(11.5)^{*}$ & \multirow{4}{*}{$\begin{array}{l}<0.0001^{* \dagger} \\
<0.0001^{\dagger}\end{array}$} \\
\hline \multicolumn{4}{|l|}{ Timing of death } & \\
\hline Before intervention & $196(41.9)$ & $2720(55.8)$ & 2916 (54.6) & \\
\hline After intervention & $272(58.1)$ & $2153(44.2)$ & $2425(45.4)$ & \\
\hline \multicolumn{4}{|l|}{ Study site } & \multirow[t]{7}{*}{$<0.0001^{\dagger}$} \\
\hline 1 & $45(9.6)$ & $993(20.3)$ & 1038 (19.4) & \\
\hline 2 & $67(14.3)$ & $808(16.6)$ & $875(16.4)$ & \\
\hline 3 & $125(26.7)$ & $739(15.2)$ & $864(16.2)$ & \\
\hline 4 & $49(10.5)$ & $564(11.6)$ & $613(11.5)$ & \\
\hline 5 & 87 (18.6) & $1018(20.9)$ & 1105 (20.7) & \\
\hline 6 & $95(20.3)$ & $751(15.4)$ & $846(15.9)$ & \\
\hline \multicolumn{5}{|c|}{ Psychiatric comorbidities (could have one or more) } \\
\hline Anxiety disorders & $171(36.5)$ & $607(12.5)$ & 778 (14.6) & \multirow{17}{*}{$\begin{array}{l}<0.0001^{\dagger} \\
0.43 \\
<0.0001^{\dagger} \\
<0.0001^{\dagger} \\
0.007 \\
<0.0001^{\dagger} \\
0.0004^{\dagger}\end{array}$} \\
\hline Any dementia & $45(9.6)$ & $526(10.8)$ & $571(10.7)$ & \\
\hline Major depression & $100(21.4)$ & $233(4.8)$ & $333(6.2)$ & \\
\hline Alcohol use disorder & $50(10.7)$ & $165(3.4)$ & $215(4.0)$ & \\
\hline Schizophrenia & $29(6.2)$ & $179(3.7)$ & $208(3.9)$ & \\
\hline Drug use disorder (non-nicotine) & $55(11.8)$ & $139(2.9)$ & $194(3.6)$ & \\
\hline \multicolumn{4}{|l|}{ Primary terminal diagnosis } & \\
\hline Cancer & $146(31.2)$ & 1445 (29.7) & $1591(29.8)$ & \\
\hline Dementia & $28(6.0)$ & $415(8.5)$ & $443(8.3)$ & \\
\hline Lung disease & $40(8.6)$ & $392(8.0)$ & $432(8.1)$ & \\
\hline Heart disease & $70(15.0)$ & $1018(20.9)$ & $1088(20.4)$ & \\
\hline Kidney disease & $30(6.0)$ & $252(5.2)$ & $282(5.3)$ & \\
\hline Liver disease & $47(10.4)$ & $272(5.6)$ & $319(6.0)$ & \\
\hline Brain (stroke or neurological) & $28(6.0)$ & $354(7.3)$ & $382(7.2)$ & \\
\hline HIV & $5(1.1)$ & $77(1.6)$ & $82(1.5)$ & \\
\hline Acute illness & $32(6.8)$ & $294(6.0)$ & $326(6.1)$ & \\
\hline Unexpected or none & $42(9.0)$ & $354(7.3)$ & $396(7.4)$ & \\
\hline
\end{tabular}

135 patients had missing data and were not included. Data presented as number (column \%), unless otherwise indicated

BEACON Best Practices for End-of-Life Care for Our Nation's Veterans, VA Veterans Affairs, PTSD post-traumatic stress disorder, SD standard deviation, HIV human immunodeficiency virus

*Continuous variable, $t$ test for statistical significance

${ }^{\dagger}$ Statistically significant after Bonferroni correction, $p<0.0016$

The most common primary terminal diagnosis was cancer, followed by heart disease, regardless of PTSD diagnosis.

\section{Care Patterns in Veterans With and Without PTSD}

Table 2 describes the differences in outcomes for veterans with and without PTSD. Patients with PTSD had significantly more VA hospital admissions and ER visits than those without PTSD (admissions: PTSD 2.8, no PTSD 2.4, $p<0.0001$; ER visits: 3.2 vs $2.5, p<0.0001)$. Patients with PTSD were significantly more likely to have an advanced directive, $48.1 \%$ vs $37.9 \%(p<0.0001)$. However, there was a trend towards fewer DNR orders in patients with PTSD, $66.5 \%$ vs $71.0 \%(p=0.037)$. During the final admission, for veterans with PTSD, there was a trend towards any ICU use $(49.6 \%$ vs $42.7 \%, p=0.004)$, but deaths in the medical or cardiac ICU were less likely. There were no statistically significant differences noted in length of stay or use of invasive treatments. However, there were significant differences in administration of symptom-relieving medications in the last 7 days of life.
Patients with PTSD were more likely to have received an opioid, benzodiazepine, or an antipsychotic at any time during the last 7 days of life and were also more likely to have received each medication class in both the last $48 \mathrm{~h}$ of life and in the time period from $49 \mathrm{~h}$ to 7 days before death.

\section{Predictors of Medication Administration Throughout the Last 7 Days of Life}

To model our assumption that patients with PTSD were more symptomatic, and thus consistently requiring symptom-relieving medication, we chose the data category of "both" observed time periods (receiving medication in the last $48 \mathrm{~h}$ of life and in the time period from $49 \mathrm{~h}$ to 7 days before death) for our GEE drug class models. As opioids, benzodiazepines, and antipsychotics tend to be used for different symptom clusters, we examined predictors of administration for each drug class separately and for all three classes combined using hierarchical GEE models (Appendix Table 6-online). PTSD was significant in the univariate models. However, in fully adjusted models, PTSD was only significant in the antipsychotic model (Table 3 ). 
Table 2 Process of Care Outcomes of 5341 Veterans in the BEACON Intervention Trial Who Died as Inpatients in at One of 6 VA Medical Facilities, Stratified by PTSD Diagnosis

\begin{tabular}{|c|c|c|c|c|}
\hline \multirow[t]{2}{*}{$\overline{\text { Outcomes }}$} & \multicolumn{2}{|c|}{ PTSD diagnosis } & \multirow[t]{2}{*}{ Total $(n=5341)$} & \multirow[t]{2}{*}{ Chi-square, $p$ value } \\
\hline & Yes $(n=468)$ & No $(n=4873)$ & & \\
\hline \multicolumn{5}{|l|}{ Mean number of VA admissions } \\
\hline In last 12 months of life (SD)* & $2.8(2.1)^{*}$ & $2.4(1.8)^{*}$ & $2.4(1.8)^{*}$ & $<0.0001 *^{\dagger}$ \\
\hline \multicolumn{5}{|l|}{ Mean number of ER visits } \\
\hline In last 12 months of life (SD)* & $3.2(3.7)^{*}$ & $2.5(2.8)^{*}$ & $2.6(2.9)^{*}$ & $<0.0003 *^{\dagger}$ \\
\hline \multicolumn{5}{|l|}{ Events - any time prior to death } \\
\hline Advanced directive documented & $225(48.1)$ & 1847 (37.9) & $2072(38.8)$ & $<0.0001^{\dagger}$ \\
\hline Do not resuscitate order present & $311(66.5)$ & $3462(71.0)$ & $3773(70.6)$ & 0.037 \\
\hline \multicolumn{5}{|l|}{ Events-Final Inpatient Admission } \\
\hline Mean length of stay in days (SD)* & $11.3(78.6)^{*}$ & $21.4(146.9)^{*}$ & $23.1(172.4)^{*}$ & $0.143 *$ \\
\hline Mean days of IV infusion (SD)* & $5.0(2.5)^{*}$ & $5.0(2.5)^{*}$ & $5.0(2.5) *$ & $0.85^{*}$ \\
\hline Palliative care consult & $88(18.8)$ & $787(16.2)$ & $875(16.3)$ & 0.139 \\
\hline Any time spent in ICU & $232(49.6)$ & $2080(42.7)$ & $2312(43.3)$ & 0.004 \\
\hline Pastoral care note (during last 7 days) & $289(61.8)$ & $2821(57.9)$ & $3110(58.2)$ & 0.106 \\
\hline IV infusing at death & $334(71.4)$ & $3444(70.7)$ & $3778(70.7)$ & 0.75 \\
\hline Nasogastric or feeding tube at death & $188(40.2)$ & $1904(39.1)$ & $2092(39.2)$ & 0.64 \\
\hline In restraints at death & $77(16.5)$ & $801(16.4)$ & $878(16.4)$ & 0.99 \\
\hline Family present at death & $201(42.9)$ & $2095(43.0)$ & $2296(43.0)$ & 0.99 \\
\hline \multicolumn{4}{|l|}{ Location of death } & 0.006 \\
\hline Medical/Cardiac ICU & $138(29.5)$ & $1873(38.4)$ & $2011(37.7)$ & \\
\hline Emergency room or urgent care & $5(1.1)$ & $82(1.7)$ & $87(1.6)$ & \\
\hline Medical ward & $185(39.5)$ & $1685(34.6)$ & $1870(35.0)$ & \\
\hline Surgical ICU & $47(10.0)$ & $395(8.1)$ & $442(8.3)$ & \\
\hline Surgical ward & $27(5.8)$ & $219(4.5)$ & $246(4.6)$ & \\
\hline Palliative care unit & $25(5.3)$ & $196(4.0)$ & $221(4.1)$ & \\
\hline Other & $41(8.8)$ & $423(8.7)$ & $464(8.7)$ & \\
\hline \multicolumn{5}{|l|}{ Medications given in last 7 days } \\
\hline \multicolumn{5}{|l|}{ Opioids } \\
\hline Ever given & $343(73.3)$ & $3328(68.3)$ & $3671(68.7)$ & 0.026 \\
\hline When given & & & & 0.004 \\
\hline Never & $125(26.7)$ & $1545(31.7)$ & $1670(31.3)$ & \\
\hline $0-48 \mathrm{~h}$ only & $114(24.4)$ & $1283(26.3)$ & $1397(26.2)$ & \\
\hline $49 \mathrm{~h}-7$ days only & $42(9.0)$ & $502(10.3)$ & $544(10.2)$ & \\
\hline Both time periods & $187(40.0)$ & $1543(31.7)$ & $1730(32.4)$ & \\
\hline \multicolumn{5}{|l|}{ Benzodiazepines } \\
\hline Ever given & $222(47.4)$ & $1936(35.6)$ & $2158(40.4)$ & $0.0012^{\dagger}$ \\
\hline When given & & & & $0.0008^{\dagger}$ \\
\hline Never & $246(52.6)$ & $2937(60.3)$ & $3183(59.6)$ & \\
\hline $0-48 \mathrm{~h}$ only & $74(15.8)$ & $769(15.8)$ & $843(15.8)$ & \\
\hline $49 \mathrm{~h}-7$ days only & $58(12.4)$ & $524(10.8)$ & $582(11.0)$ & \\
\hline Both time periods & $90(19.2)$ & $643(13.2)$ & 733 (13.7) & \\
\hline \multicolumn{5}{|l|}{ Antipsychotics } \\
\hline Ever given & $123(26.3)$ & $763(17.8)$ & $886(16.6)$ & $<0.0001^{\dagger}$ \\
\hline When given & & & & $<0.0001^{\dagger}$ \\
\hline Never & $345(73.7)$ & $4110(84.3)$ & 4455 (83.4) & \\
\hline $0-48 \mathrm{~h}$ only & $32(6.8)$ & $217(4.5)$ & $249(4.7)$ & \\
\hline $49 \mathrm{~h}-7$ days only & $44(9.4)$ & $260(5.3)$ & $304(5.7)$ & \\
\hline Both time periods & $47(10.0)$ & $286(5.9)$ & $333(6.2)$ & \\
\hline
\end{tabular}

135 patients had missing data and were not included. Data presented as number (column \%), unless otherwise indicated

BEACON Best Practices for End-of-Life Care for Our Nation's Veterans, VA Veterans Affairs, PTSD post-traumatic stress disorder, SD standard deviation, ER emergency room, IV intravenous, ICU intensive care unit

*Continuous variable, $t$ test for statistical significance

${ }^{\dagger}$ Statistically significant after Bonferroni correction, $p<0.0016$

Table 4 illustrates the full models from Table 3, including covariates. Year of death was significant in each model. Older age was also significant, associated with a $13 \%$ lower likelihood of receiving opioids, a $15 \%$ lower likelihood of receiving benzodiazepines, and a $24 \%$ lower likelihood of receiving all three drug classes together.

Cancer and major depression were significant in both the opioid and benzodiazepine models. Patients with depression were $39 \%$ more likely to receive opioids and $49 \%$ more likely to receive benzodiazepines. In the benzodiazepine model, significant predictors included year of death, age, race, anxiety, alcohol use disorder, drug use disorder, and cancer. PTSD was only significant in the antipsychotic model, along with year of death and schizophrenia.

To examine if PTSD remained a significant predictor of VA ER visits or hospitalizations in the last 12 months of life, we also created GEE relative risk models with the same covariates as the drug class models. A PTSD diagnosis was associated with 1.09 times more admissions $(95 \%$ CI $1.03-1.16, p=0.034)$ and 1.10 times more ER visits (95\% CI $0.98-1.24, p=0.17$ ). 
Table 3 Generalized Estimating Equation (GEE) Models for Odds of PTSD Associated with Administration of Each Listed Medication Class in Both Time Periods (in the Last $48 \mathrm{~h}$ of Life and in the Last 2-7 Days of Life)

\begin{tabular}{|c|c|c|}
\hline$\overline{\text { Model }}$ & $\begin{array}{l}\text { Odds ratio } \\
\text { (95\% confidence interval) }\end{array}$ & $p$ value \\
\hline \multicolumn{3}{|l|}{ Opioids } \\
\hline PTSD alone & $1.36(1.04-1.79)$ & 0.034 \\
\hline Full model* & $1.18(0.89-1.55)$ & 0.192 \\
\hline \multicolumn{3}{|c|}{ Benzodiazepines } \\
\hline PTSD alone & $1.50(1.20-1.18)$ & 0.006 \\
\hline Full model* & $1.06(0.75-1.49)$ & 0.703 \\
\hline \multicolumn{3}{|l|}{ Antipsychotics } \\
\hline PTSD alone & $1.75(1.40-2.19)$ & 0.001 \\
\hline Full model* & $1.52(1.06-2.18)$ & $0.030^{\dagger}$ \\
\hline \multicolumn{3}{|c|}{ All three drug classes } \\
\hline PTSD alone & $2.34(1.11-4.95)$ & 0.032 \\
\hline Full model* & $1.62(0.48-5.46)$ & 0.358 \\
\hline
\end{tabular}

All models included clustering by medical center

PTSD post-traumatic stress disorder

*Full models adjusted for year of death, in intervention phase of primary study, age at death, race, gender, anxiety, dementia, major depression, non-nicotine drug use disorder, alcohol use disorder, schizophrenia, and a primary terminal diagnosis of cancer

${ }^{\top}$ Statistically significant in full model, $p<0.05$

\section{DISCUSSION}

Our findings provide new empirical evidence supporting the hypothesis that individuals with PTSD have increased symptom burden in the final months and days of life. In comparing veterans with and without PTSD dying in a VA medical facility, those with PTSD were more likely to have previously been admitted to a VA facility in the past 12 months and were more likely to have received antipsychotics in the last 7 days of life. PTSD, by definition, requires exposure to a traumatic event involving near death or threatened death. ${ }^{15}$ Subsequent trauma can cause a recurrence or worsening of PTSD symptoms. ${ }^{61,} 62$ Therefore, we hypothesized that as death nears, PTSD symptoms would worsen. Obtaining evidence that PTSD impacts the end of life will facilitate future work exploring this impact and developing interventions to improve the end-of-life experience.

Because prospective data collection in hospice and palliative care populations can be challenging, ${ }^{63,64}$ we used medications and healthcare utilization as proxies for PTSD symptom burden. Patients with psychiatric illness typically have increased healthcare utilization. ${ }^{3-6}$ Those in mid-life with PTSD may have the highest utilization. ${ }^{65}$ Because this utilization is associated with symptom burden, ${ }^{65-67}$ we hypothesized that continued or worsening PTSD symptoms would thus contribute to increased end-of-life healthcare utilization.

Moving beyond symptoms, because PTSD is frequently comorbid with other psychiatric illnesses, ${ }^{17,} 18,68$ we needed to determine if PTSD was a separately detectable issue at the end-of-life. Importantly, we found that only PTSD and schizophrenia were associated with administration of antipsychotics in the last 7 days of life. The schizophrenia finding was unsurprising, as the data did not consider medications prior to the last 7 days of life. While patients with schizophrenia would continue to receive antipsychotics in the final days of life, antipsychotics are not recommended for PTSD treatment ${ }^{69}$ nor are they routinely prescribed for PTSD in the VA setting. ${ }^{70,71}$

For example, antipsychotic prescription rates in PTSD in VA in 2009 were $5.1 \%$ for second-generation antipsychotics in veterans age 65 and older ${ }^{71}$ and $13.9 \%$ for any antipsychotic overall. ${ }^{70}$ Our data was collected between 2005 and 2011, and the rates of receiving any antipsychotic in the last 7 days of life with and without PTSD were $26.3 \%$ and $15.6 \%$, respectively. Antipsychotics have been associated with PTSD in patients with dementia. ${ }^{71}$ However, we controlled for dementia, and it was not associated with antipsychotic administration.

Antipsychotics are commonly prescribed in palliative care and hospice settings ${ }^{72,73}$ and are recommended for short-term treatment of delirium. ${ }^{74,}{ }^{75}$ However, black box warnings recommend against the long-term use of antipsychotics in elderly patients or those with dementia. ${ }^{76,77}$ Antipsychotics are less commonly prescribed upon hospice admission than opioids or benzodiazepines. ${ }^{73,78}$ However, prescriptions increase as death nears, ${ }^{73,78}$ initiated an average of 2-5 days prior to death. ${ }^{73}$ For additional context, in veterans receiving palliative care, but not actively dying, there was no difference in antipsychotic prescription rates between patients with or without PTSD. ${ }^{79}$ We cannot be certain, but these studies suggest that the antipsychotics provided to veterans with PTSD in our study were newly ordered in response to symptoms in the imminently dying.

To potentially explain our observed association with PTSD and antipsychotics, PTSD has been associated with anesthesia emergence delirium $^{80-82}$ and ICU delirium. ${ }^{83,}{ }^{84}$ However, to date, PTSD has not been identified as a risk factor for terminal delirium, ${ }^{85,}{ }^{86}$ which is treated first-line with antipsychotics. ${ }^{74} \mathrm{~A}$ detailed discussion about the psycho-neuro-pathophysiology of PTSD and how it may predispose to delirium is beyond the context of this paper but has been described elsewhere. ${ }^{87-91}$ Briefly, in a semi-conscious state, an unknown stimulus, such as monitor beeping, is often interpreted as something dangerous, something to fear, especially in patients with PTSD. Generally, patients with PTSD are also less able to extinguish a fear response. Therefore, it is more likely that the continued fear response signal will cause physical agitation, such as pulling at tubes or lines. While some literature suggests that ICU exposure causes PTSD and not the opposite, ${ }^{48,50}$ controlling for pre-existing PTSD or psychiatric illness removes this association. ${ }^{84,92,93}$

Due to the high psychiatric comorbidity in PTSD and in our study, it was unsurprising that PTSD was not associated with the administration of opioids or with benzodiazepines in the last 7 days of life. By controlling for comorbid psychiatric diagnoses, we were attempting to isolate the effects of PTSD on end-of-life medication administration. However, in patients with multiple psychiatric diagnoses, attributing one specific symptom to one specific diagnosis can be challenging. ${ }^{94,} 95$ Still, we feel that the correlations observed between opioids and depression and benzodiazepines with depression and anxiety suggest that in the final days of life, psychiatric illness may contribute to symptom burden. 
Table 4 Full Generalized Estimating Equation (GEE) Models, Including Covariates, for Odds of PTSD Associated with Administration of Each Listed Medication Class in Both Time Periods (in the Last $48 \mathrm{~h}$ of Life and in the Last 2-7 Days of Life)

\begin{tabular}{|c|c|c|c|c|c|c|c|c|}
\hline \multirow[t]{3}{*}{ Variables } & \multicolumn{8}{|c|}{ Drug class GEE models } \\
\hline & \multicolumn{2}{|l|}{ Opioids } & \multicolumn{2}{|l|}{ Benzodiazepines } & \multirow{2}{*}{$\begin{array}{l}\text { Antipsychotics } \\
\text { Odds ratio } \\
(95 \% \text { CI })\end{array}$} & \multicolumn{3}{|c|}{ All three drug classes } \\
\hline & $\begin{array}{l}\text { Odds ratio } \\
\text { (95\% CI) }\end{array}$ & $p$ value & Odds ratio $(95 \% \mathrm{CI})$ & $p$ value & & $p$ value & $\begin{array}{l}\text { Odds ratio } \\
\text { (95\% CI) }\end{array}$ & $p$ value \\
\hline PTSD & $1.18(0.89-1.55)$ & 0.192 & $1.06(0.75-1.49)$ & 0.703 & $1.52(1.06-2.18)$ & $0.030 *$ & $1.62(0.48-5.46)$ & 0.358 \\
\hline Year (vs 2011) & & $<0.001^{\dagger}$ & & $<0.001^{\dagger}$ & & $<0.001^{\dagger}$ & & $0.0046^{*}$ \\
\hline 2005 & $0.93(0.56-1.54)$ & & $0.80(0.45-1.40)$ & & $0.62(0.44-0.88)$ & & $0.32(0.02-4.28)$ & \\
\hline 2006 & $0.78(0.47-1.31)$ & & $0.69(0.41-1.16)$ & & $0.59(0.37-0.93)$ & & $0.24(0.02-2.69)$ & \\
\hline 2007 & $0.73(0.48-1.11)$ & & $0.79(0.43-1.47)$ & & $0.41(0.28-0.60)$ & & $0.10(0.02-0.41)$ & \\
\hline 2008 & $0.80(0.54-1.17)$ & & $0.77(0.55-1.08)$ & & $0.48(0.33-0.68)$ & & $0.22(0.03-1.63)$ & \\
\hline 2009 & $0.90(0.55-1.48)$ & & $0.90(0.52-1.55)$ & & $0.53(0.44-0.65)$ & & $0.41(0.10-1.74)$ & \\
\hline 2010 & $0.95(0.65-1.39)$ & & $0.92(0.61-1.39)$ & & $0.55(0.36-0.85)$ & & $0.36(0.11-1.21)$ & \\
\hline $\begin{array}{l}\text { Non-intervention } \\
\text { arm }\end{array}$ & $0.89(0.69-1.15)$ & 0.298 & $1.19(0.95-1.49)$ & 0.098 & $0.75(0.45-1.25)$ & 0.21 & $1.05(0.12-9.21)$ & 0.954 \\
\hline $\begin{array}{l}\text { Older age } \\
\text { (by decade) }\end{array}$ & $0.87(0.81-0.93)$ & $<0.001^{\dagger}$ & $0.85(0.80-0.91)$ & $<0.001^{\dagger}$ & $1.08(0.96-1.21)$ & 0.193 & $0.76(0.61-0.95)$ & $0.015^{*}$ \\
\hline White race & $0.79(0.62-1.02)$ & 0.067 & $0.78(0.66-0.92)$ & $0.012^{*}$ & $0.92(0.66-1.28)$ & 0.53 & $0.99(0.37-2.65)$ & 0.97 \\
\hline Female gender & $1.14(0.57-2.26)$ & 0.652 & $0.83(0.39-1.74)$ & 0.54 & $0.75(0.35-1.62)$ & 0.385 & $1.73(0.34-8.96)$ & 0.429 \\
\hline Anxiety & $1.07(0.84-1.37)$ & 0.51 & $1.60(1.19-2.14)$ & $0.009^{*}$ & $1.12(0.77-1.64)$ & 0.472 & $1.42(0.46-4.44)$ & 0.462 \\
\hline Dementia & $0.92(0.59-1.43)$ & 0.646 & $0.68(0.48-0.95)$ & $0.032 *$ & $1.65(0.99-2.73)$ & 0.052 & $2.03(0.83-4.98)$ & 0.099 \\
\hline Major depression & $1.35(1.13-1.61)$ & $0.0075^{*}$ & $1.49(1.14-1.94)$ & $0.012 *$ & $1.49(0.78-2.85)$ & 0.178 & $1.27(0.54-3.01)$ & 0.506 \\
\hline $\begin{array}{l}\text { Alcohol use } \\
\text { disorder }\end{array}$ & $0.98(0.54-1.78)$ & 0.943 & $2.15(1.50-3.07)$ & $0.003^{*}$ & $0.99(0.43-2.29)$ & 0.982 & $1.34(0.29-6.24)$ & 0.645 \\
\hline Schizophrenia & $0.89(0.58-1.37)$ & 0.513 & $0.91(0.59-1.39)$ & 0.579 & $4.35(2.42-7.81)$ & $0.0013^{*}$ & $1.88(0.34-10.49)$ & 0.39 \\
\hline Drug use disorder & $1.51(1.002-2.27)$ & $0.049 *$ & $1.45(1.08-1.95)$ & $0.022 *$ & $1.45(0.55-3.79)$ & 0.371 & $1.94(0.80-4.73)$ & 0.112 \\
\hline $\begin{array}{l}\text { Non-cancer } \\
\text { terminal } \\
\text { diagnosis }\end{array}$ & $0.45(0.38-0.53)$ & $<0.001^{\dagger}$ & $0.85(0.74-0.98)$ & $0.032 *$ & $0.77(0.52-1.15)$ & 0.159 & $0.53(0.28-1.004)$ & 0.0509 \\
\hline
\end{tabular}

PTSD post-traumatic stress disorder, CI confidence interval

*p value is statistically significant, $p<0.05$

${ }^{*} p$ value $<0.0001$ and statistically significant

${ }^{*}$ Non-cancer terminal diagnosis includes all primary terminal diagnoses other than a cancer diagnosis

We also considered that symptom burden may lead to increased healthcare utilization. We found that VA hospitalizations in the last 12 months of life were increased in comparing patients with and without PTSD; ER visits were not statistically different. Generally, patients with psychiatric illness, including those with PTSD, have increased healthcare utilization, ${ }^{65-67}$ if they have adequate healthcare access and do not feel stigmatized. ${ }^{96,97}$ As VA provides expertise in veteran issues, especially in PTSD, ${ }^{51}$ veterans may feel less stigma and more comfortable seeking VA care. ${ }^{98,99}$ In contrast, in Washington state, patients with psychiatric illness had decreased inpatient and ICU utilization, with increased ER use in the last 30 days of life. ${ }^{100}$ However, all psychiatric illnesses in this study were grouped together, which may not be ideal, as end-of-life care patterns can be more nuanced. For example, pre-existing depression was associated with earlier hospice use and less acute care in patients with lung cancer. ${ }^{101}$ A similar study found that patients with pre-existing depression or post-cancer depression both were more likely to use hospice than those without depression. ${ }^{102}$ However, patients with lung cancer and increased depression or anxiety symptoms were more likely to receive chemotherapy in the last 14 days of life. ${ }^{103}$ Thus, further study of psychiatric illness and its impact on end-of-life healthcare utilization is needed.

It was unexpected that advanced directive documentation was more common in veterans with PTSD, because we had hypothesized that avoidant coping in $\mathrm{PTSD}^{15}$ would decrease advance care planning (ACP). However, it is possible that repeated health system contact via higher utilization led to this finding. ${ }^{104,105}$ In contrast, there was a trend towards veterans with PTSD being less likely to have a DNR order. Thus, it is difficult to discern the care choices made, or if PTSD impacted these choices. It is also possible that the BEACON intervention itself, emphasizing ACP and decreasing unwanted aggressive end-of life care, impacted our ACP findings.

We acknowledge that defining PTSD based on the patient problem list is a limitation. Our PTSD rate was $8.7 \%$, with a median age of 65 for those patients, compared to lifetime PTSD prevalence of $3.7 \%$ for US veterans age 65 or older. $^{68}$ In VA, using ICD-9 codes to detect PTSD has a $72-84 \%$ positive predictive value. ${ }^{106}$ Also, using ICD-9 codes for PTSD has been demonstrated to adequately separate patients with the most PTSD symptoms (true positives) from those with the least symptoms (true negatives), ${ }^{107}$ symptoms being a dimension of interest in our study. However, without further information, PTSD rates using the problem list would be less than lifetime rates. Thus, our PTSD rate is likely an underestimate. However, an underestimate would bias the findings toward the null.

Further, our study focused on predominantly male veterans, dying within VA medical centers. Our findings only generalize 
to similar settings, as patients dying at home may have different end-of-life symptoms and utilization patterns. Non-VA healthcare use was unaccounted for and could have influenced our utilization findings. Additionally, descriptions of patient symptoms, rationales for medication administration, and PTSD severity were lacking. Other possible confounders, such as chronic pain, traumatic brain injury, or socioeconomic disadvantage, could not be accounted for. The strengths of this study include its large sample size and detailed information about end-of-life care processes metrics. Also, with $31.6 \%$ African-Americans, this sample was more racially representative than other VA-based studies, important because of the higher PTSD rates noted in minorities. ${ }^{18,68}$

In conclusion, our findings provide new evidence suggesting increased symptom burden for individuals with PTSD at the end-of-life and that PTSD may be a separate risk factor for terminal delirium. Future studies should examine the impact of PTSD and other psychiatric illnesses on the end-of-life experience in all patient populations, not only veterans. The impact of symptom severity, prior treatment for psychiatric illness, physical and psychiatric comorbidities, and type of trauma experienced should also be considered.

Acknowledgments: We thank Paul E. Holtzheimer, MD, for his review and comments during the preparation of this manuscript

Corresponding Author: Kathleen E. Bickel, MD, MPhil, MS; University of Colorado School of Medicine Rocky Mountain VA Medical Center, Mail Stop B180, Academic Office One, 12631 E 17th Ave, Room 8407, Aurora, CO 80045-2527, USA (e-mail: kathleen. bickel@cuanschutz.edu).

Funding Information This research was funded by a grant from the Veterans Administration Health Services Research and Development (HSR\&D) Program, "Impact of An Intervention to Improve Care at Life's End in VA Medical Centers" (IIR 03-126, PI: KL Burgio, Co-PI: FA Bailey). Dr. Bickel was funded by the National Institute on Aging of the National Institutes of Health under award number 5T32AG044296. The views expressed are those of the authors and do not necessarily reflect the position or policy of the Department of Veterans Affairs, the United States Government, or the National Institutes of Health.

\section{Compliance with Ethical Standards:}

Conflict of Interest: The authors declare that they do not have a conflict of interest.

\section{REFERENCES}

1. Jackson VA, Jacobsen J, Greer JA, Pirl WF, Temel JS, Back AL. The cultivation of prognostic awareness through the provision of early palliative care in the ambulatory setting: a communication guide. $\mathrm{J}$ Palliat Med. 2013;16(8):894-900.

2. Wilson KG, Chochinov HM, Skirko MG, et al. Depression and anxiety disorders in palliative cancer care. Journal of pain and symptom management. 2007;33(2): 118 .

3. Pan X, Sambamoorthi U. Health care expenditures associated with depression in adults with cancer. $J$ Commun Support Oncol 2015;13(7):240-7.

4. Unutzer J, Schoenbaum M, Katon WJ, et al. Healthcare costs associated with depression in medically Ill fee-for-service medicare participants. Journal of the American Geriatrics Society. 2009;57(3):506-10.

5. Himelhoch S, Weller WE, Wu AW, Anderson GF, Cooper LA. Chronic medical illness, depression, and use of acute medical services among Medicare beneficiaries. Med Care. 2004;42(6):512-21.

6. Yoon J, Yano EM, Altman L, et al. Reducing costs of acute care for ambulatory care-sensitive medical conditions: the central roles of comorbid mental illness. Med Care. 2012;50(8):705-13.

7. Waserstein G, Partin C, Cohen D, Schettler P, Kinkead B, Rapaport MH. The prevalence and impact of psychiatric symptoms in an undiagnosed diseases clinical program. PloS one. 2019;14(6):e0216937.

8. Woo JM, Jeon HJ, Noh E, et al. Importance of remission and residual somatic symptoms in health-related quality of life among outpatients with major depressive disorder: a cross-sectional study. Health and quality of life outcomes. 2014;12:188.

9. Revicki DA, Brandenburg N, Matza L, Hornbrook MC, Feeny D. Health-related quality of life and utilities in primary-care patients with generalized anxiety disorder. Quality of life research : an international journal of quality of life aspects of treatment, care and rehabilitation. 2008;17(10): 1285-94.

10. Vigo D, Thornicroft G, Atun R. Estimating the true global burden of mental illness. Lancet Psychiatry. 2016;3(2):171-8.

11. Parks J, Svendsen D, Singer P, Foti ME, Mauer B. Morbidity and mortality in people with serious mental illness. Alexandria, VA: National Association of State Mental Health Program Directors (NASMHPD) Medical Directors Council. 2006;25(4).

12. Holubova M, Prasko J, Ociskova M, et al. Quality of life and coping strategies of outpatients with a depressive disorder in maintenance therapy - a cross-sectional study. Neuropsychiatric disease and treatment. 2018;14:73-82.

13. Bockting CL, Hollon SD, Jarrett RB, Kuyken W, Dobson K. A lifetime approach to major depressive disorder: The contributions of psychological interventions in preventing relapse and recurrence. Clin Psychol Rev. 2015;41:16-26.

14. Buckman JEJ, Underwood A, Clarke $\mathbf{K}$, et al. Risk factors for relapse and recurrence of depression in adults and how they operate: A fourphase systematic review and meta-synthesis. Clin Psychol Rev. 2018;64:13-38.

15. American Psychiatric Association., American Psychiatric Association DSM-5 Task Force. Trauma- and stressor-related disorders. In Diagnostic and statistical manual of mental disorders : DSM-5. 5th ed. Washington, D.C.: American Psychiatric Association; 2013:xliv, 947 p.

16. van der Kolk BA. The body keeps the score: memory and the evolving psychobiology of posttraumatic stress. Harvard review of psychiatry. 1994; 1(5):253-65.

17. Wisco BE, Marx BP, Miller MW, et al. Probable Posttraumatic Stress Disorder in the US Veteran Population According to DSM-5: Results From the National Health and Resilience in Veterans Study. J Clin Psychiatry. 2016;77(11):1503-10.

18. Pietrzak RH, Goldstein RB, Southwick SM, Grant BF. Prevalence and Axis I comorbidity of full and partial posttraumatic stress disorder in the United States: results from Wave 2 of the National Epidemiologic Survey on Alcohol and Related Conditions. J Anxiety Disord. 2011;25(3):45665.

19. Defrin R, Schreiber S, Ginzburg K. Paradoxical Pain Perception in Posttraumatic Stress Disorder: The Unique Role of Anxiety and Dissociation. J Pain. 2015;16(10):961-70.

20. Mostoufi S, Godfrey KM, Ahumada SM, et al. Pain sensitivity in posttraumatic stress disorder and other anxiety disorders: a preliminary case control study. Ann Gen Psychiatry. 2014;13(1):31.

21. Gomez-Perez L, Lopez-Martinez AE. Association of trauma, posttraumatic stress disorder, and experimental pain response in healthy young women. Clin J Pain. 2013;29(5):425-34.

22. Loeb TB, Joseph NT, Wyatt GE, et al. Predictors of somatic symptom severity: The role of cumulative history of trauma and adversity in a diverse community sample. Psychol Trauma. 2018;10(5):491-8.

23. Bae SM, Kang JM, Chang HY, Han W, Lee SH. PTSD correlates with somatization in sexually abused children: Type of abuse moderates the effect of PTSD on somatization. PloS one. 2018;13(6):e0199138.

24. Magruder KM, Goldberg J, Forsberg CW, et al. Long-Term Trajectories of PTSD in Vietnam-Era Veterans: The Course and Consequences of PTSD in Twins. J Trauma Stress. 2016;29(1):5-16.

25. Steinert C, Hofmann M, Leichsenring F, Kruse J. The course of PTSD in naturalistic long-term studies: high variability of outcomes. A systematic review. Nord J Psychiatry. 2015;69(7):483-96. 
26. Bonanno GA, Brewin CR, Kaniasty K, Greca AML. Weighing the Costs of Disaster: Consequences, Risks, and Resilience in Individuals, Families, and Communities. Psychological Science in the Public Interest. 2010;11(1): 1-49.

27. Horesh D, Solomon Z, Keinan G, Ein-Dor T. The clinical picture of late-onset PTSD: a 20-year longitudinal study of Israeli war veterans. Psychiatry Res. 2013;208(3):265-73.

28. Pietrzak RH, Van Ness PH, Fried TR, Galea S, Norris FH. Trajectories of posttraumatic stress symptomatology in older persons affected by a large-magnitude disaster. J Psychiatric Res. 2013;47(4):520-6.

29. Port CL, Engdahl B, Frazier P. A longitudinal and retrospective study of PTSD among older prisoners of war. Am J Psychiatry. 2001;158(9):1474-9.

30. Steenkamp MM, Schlenger WE, Corry N, et al. Predictors of PTSD 40 years after combat: Findings from the National Vietnam Veterans longitudinal study. Depress Anxiety. 2017;34(8):711-22.

31. Mota N, Tsai J, Kirwin PD, et al. Late-life exacerbation of PTSD symptoms in US veterans: results from the National Health and Resilience in Veterans Study. J Clin Psychiatry. 2016;77(3):34854.

32. Horesh D, Solomon Z, Zerach G, Ein-Dor T. Delayed-onset PTSD among war veterans: the role of life events throughout the life cycle. Social Psychiatry and Psychiatric Epidemiology. 2011;46(9):863-70.

33. Maniates H, Stoop TB, Miller MW, Halberstadt L, Wolf EJ. StressGenerative Effects of Posttraumatic Stress Disorder: Transactional Associations Between Posttraumatic Stress Disorder and Stressful Life Events in a Longitudinal Sample. Journal of Traumatic Stress. 2018;31(2): 191-201.

34. Hiskey S, Luckie M, Davies S, Brewin CR. The emergence of posttraumatic distress in later life: a review. J Geriatr Psychiatry Neurol. 2008;21(4):232-41.

35. Macleod AD. The reactivation of post-traumatic stress disorder in later life. Aust N Z J Psychiatry. 1994;28(4):625-34.

36. Sachs-Ericsson N, Joiner TE, Cougle JR, Stanley IH, Sheffler JL. Combat Exposure in Early Adulthood Interacts with Recent Stressors to Predict PTSD in Aging Male Veterans. The Gerontologist. 2015.

37. Davison EH, Kaiser AP, Spiro A, 3rd, Moye J, King LA, King DW. From Late-Onset Stress Symptomatology to Later-Adulthood Trauma Reengagement in Aging Combat Veterans: Taking a Broader View. The Gerontologist. 2016;56(1):14-21.

38. Davison EH, Pless AP, Gugliucci MR, et al. Late-Life Emergence of Early-Life Trauma: The Phenomenon of Late-Onset Stress Symptomatology Among Aging Combat Veterans. Research on Aging. 2006 January 1, 2006;28(1):84-114.

39. Gradus JL. Prevalence and prognosis of stress disorders: a review of the epidemiologic literature. Clin Epidemiol. 2017;9:251-60.

40. Kessler RC, Berglund P, Demler O, Jin R, Merikangas KR, Walters EE. Lifetime prevalence and age-of-onset distributions of DSM-IV disorders in the National Comorbidity Survey Replication. Arch Gen Psychiatry. 2005;62(6):593-602.

41. Kessler RC, Chiu WT, Demler O, Merikangas KR, Walters EE. Prevalence, severity, and comorbidity of 12-month DSM-IV disorders in the National Comorbidity Survey Replication. Arch Gen Psychiatry. 2005;62(6):617-27.

42. Reynolds K, Pietrzak RH, Mackenzie CS, Chou KL, Sareen J. PostTraumatic Stress Disorder Across the Adult Lifespan: Findings From a Nationally Representative Survey. Am J Geriatr Psychiatry. 2016;24(1):81-93.

43. PDQ Supportive and Palliative Care Editorial Board. Cancer-Related Post-traumatic Stress (PDQ ${ }^{\circledR)}$ ): Health Professional Version. 2015 Jan. In: PDQ Cancer Information Summaries [Internet] [Internet]. Bethesda, MD: National Cancer Institute (US). Available from: https://www.ncbi. nlm.nih.gov/books/NBK65728/.

44. Doolittle MN, DuHamel KN. Psycho-Oncology. Post-traumatic Stress Disorder Associated with Cancer Diagnosis and Treatment. 3rd ed. 2015:323-38.

45. Abbey G, Thompson SB, Hickish T, Heathcote D. A meta-analysis of prevalence rates and moderating factors for cancer-related post-traumatic stress disorder. Psychooncology. 2015;24(4):371-81.

46. Machtinger EL, Wilson TC, Haberer JE, Weiss DS. Psychological trauma and PTSD in HIV-positive women: a meta-analysis. AIDS Behav. 2012;16(8):2091-100.

47. Martin L, Kagee A. Lifetime and HIV-related PTSD among persons recently diagnosed with HIV. AIDS Behav. 2011;15(1):125-31.
48. Parker AM, Sricharoenchai T, Raparla S, Schneck KW, Bienvenu OJ, Needham DM. Posttraumatic stress disorder in critical illness survivors: a metaanalysis. Crit Care Med. 2015;43(5):1121-9.

49. Tedstone JE, Tarrier N. Posttraumatic stress disorder following medical illness and treatment. Clin Psychol Rev. 2003;23(3):409-48.

50. Righy C, Rosa RG, da Silva RTA, et al. Prevalence of post-traumatic stress disorder symptoms in adult critical care survivors: a systematic review and meta-analysis. Critical care (London, England). 2019;23(1):213

51. Institute of Medicine (U.S.). Committee on the Assessment of Ongoing Efforts in the Treatment of Posttraumatic Stress Disorder, National Academies Press (U.S.). Treatment for posttraumatic stress disorder in military and veteran populations : initial assessment. Washington, D.C.: National Academies Press,; 2012. Available from: http://www.ncbi.nlm. nih.gov/books/NBK201098/.

52. Graves RE, Freedy JR, Aigbogun NU, Lawson WB, Mellman TA, Alim TN. PTSD Treatment of African American Adults in Primary Care: The Gap Between Current Practice and Evidence-Based Treatment Guidelines. Journal of the National Medical Association. 2011;103(7):585-93.

53. Fisher MP. PTSD in the U.S. military, and the politics of prevalence. Social Science \& Medicine. 2014;115: 1-9.

54. Miele D, O'Brien EJ. Underdiagnosis of posttraumatic stress disorder in at risk youth. Journal of Traumatic Stress. 2010;23(5):591-8.

55. Bailey FA, Williams BR, Woodby LL, et al. Intervention to improve care at life's end in inpatient settings: the BEACON trial. J Gen Intern Med. 2014 Jun;29(6):836-43.

56. Diggle P, Liang K-Y, Zeger SL. Analysis of longitudinal data. Oxford, New York: Clarendon Press; Oxford University Press; 1994. xi, 253 p. p.

57. Fay MP, Graubard BI. Small-sample adjustments for Wald-type tests using sandwich estimators. Biometrics. 2001;57(4):1198-206.

58. Mancl LA, DeRouen TA. A covariance estimator for GEE with improved small-sample properties. Biometrics. 2001;57(1):126-34.

59. Pan W, Wall MM. Small-sample adjustments in using the sandwich variance estimator in generalized estimating equations. Stat Med. 2002;21(10):1429-41.

60. Kauermann G, xf, ran, Carroll RJ. A Note on the Efficiency of Sandwich Covariance Matrix Estimation. J Am Stat Assoc. 2001;96(456): 1387-96.

61. Breslau N, Chilcoat HD, Kessler RC, Davis GC. Previous exposure to trauma and PTSD effects of subsequent trauma: results from the Detroit Area Survey of Trauma. Am J Psychiatry. 1999;156(6):902-7.

62. Breslau N, Peterson EL. Assaultive violence and the risk of posttraumatic stress disorder following a subsequent trauma. Behaviour research and therapy. 2010;48(10):1063-6.

63. Abernethy AP, Capell WH, Aziz NM, et al. Ethical conduct of palliative care research: enhancing communication between investigators and institutional review boards. J Pain Symptom Manage. 2014;48(6): 121121.

64. Chen EK, Riffin C, Reid MC, et al. Why is high-quality research on palliative care so hard to do? Barriers to improved research from a survey of palliative care researchers. J Palliat Med. 2014;17(7):782-7.

65. Cohen BE, Gima K, Bertenthal D, Kim S, Marmar CR, Seal KH. Mental health diagnoses and utilization of VA non-mental health medical services among returning Iraq and Afghanistan veterans. J Gen Intern Med. 2010;25(1):18-24.

66. Kartha A, Brower V, Saitz R, Samet JH, Keane TM, Liebschutz J. The impact of trauma exposure and post-traumatic stress disorder on healthcare utilization among primary care patients. Med Care. 2008;46(4):388-93.

67. Schlenger WE, Mulvaney-Day N, Williams CS, et al. PTSD and Use of Outpatient General Medical Services Among Veterans of the Vietnam War. Psychiatric services (Washington, DC). 2016 ;67(5):543-50.

68. Smith SM, Goldstein RB, Grant BF. The association between posttraumatic stress disorder and lifetime DSM-5 psychiatric disorders among veterans: Data from the National Epidemiologic Survey on Alcohol and Related Conditions-III (NESARC-III). J Psychiatr Res. 2016 Nov;82:16-22.

69. Management of Post-Traumatic Stress Working Group. VA/DoD Clinical Practice Guideline for the Management of Posttraumatic Stress Disorder and Acute Stress Disorder. Washington, D.C.: Department of Veterans Affairs, Department of Defense; 2017. Available from: https://www. healthquality.va.gov/guidelines/MH/ptsd/VADoDPTSDCPGFinal012418.pdf.

70. Bernardy NC, Lund BC, Alexander B, Friedman MJ. Prescribing trends in veterans with posttraumatic stress disorder. J Clin Psychiatry. 2012;73(3):297-303. 
71. Semla TP, Lee A, Gurrera R, et al. Off-Label Prescribing of SecondGeneration Antipsychotics to Elderly Veterans with Posttraumatic Stress Disorder and Dementia. Journal of the American Geriatrics Society. 2017;65(8):1789-95.

72. Sera L, McPherson ML, Holmes HM. Commonly prescribed medications in a population of hospice patients. Am J Hosp Palliat Care 2014;31(2):126-31.

73. Arevalo JJ, Geijteman ECT, Huisman BAA, et al. Medication Use in the Last Days of Life in Hospital, Hospice, and Home Settings in the Netherlands. J Palliat Med. 2018;21(2):149-55.

74. Bush SH, Kanji S, Pereira JL, et al. Treating an established episode of delirium in palliative care: expert opinion and review of the current evidence base with recommendations for future development. J Pain Symptom Manage. 2014;48(2):231-48

75. Hui D, Frisbee-Hume S, Wilson A, et al. Effect of Lorazepam With Haloperidol vs Haloperidol Alone on Agitated Delirium in Patients With Advanced Cancer Receiving Palliative Care: A Randomized Clinical Trial JAMA : the journal of the American Medical Association. 2017;318(11):1047-56.

76. Reus VI, Fochtmann LJ, Eyler AE, et al. The American Psychiatric Association Practice Guideline on the Use of Antipsychotics to Treat Agitation or Psychosis in Patients With Dementia. Am J Psychiatry. 2016; 173(5):543-6.

77. Kales HC, Kim HM, Zivin $\mathbf{K}$, et al. Risk of mortality among individual antipsychotics in patients with dementia. Am J Psychiatry. 2012;169(1):71-9.

78. Masman AD, van Dijk M, Tibboel D, Baar FP, Mathot RA. Medication use during end-of-life care in a palliative care centre. International journal of clinical pharmacy. 2015;37(5):767-75

79. Kelley-Cook E, Nguyen G, Lee S, Edwards TM, Sanchez-Reilly S Medication Needs Vary for Terminally Ill Vietnam Era Veterans With and Without a Diagnosis of PTSD. Am J Hosp Palliat Care. 2016;33(7):62532.

80. McGuire JM. The incidence of and risk factors for emergence delirium in U.S. military combat veterans. J Perianesth Nurs. 2012;27(4):236-45.

81. Wilson JT. Pharmacologic, physiologic, and psychological characteristics associated with emergence delirium in combat veterans. AANA J. 2014;82(5):355-62.

82. Umholtz M, Cilnyk J, Wang CK, Porhomayon J, Pourafkari L, Nader ND. Postanesthesia emergence in patients with post-traumatic stress disorder. J Clin Anesth. 2016;34:3-10.

83. Davydow DS, Gifford JM, Desai SV, Needham DM, Bienvenu OJ. Posttraumatic stress disorder in general intensive care unit survivors: a systematic review. Gen Hosp Psychiatry. 2008;30(5):421-34.

84. Wolters AE, Peelen LM, Welling MC, et al. Long-Term Mental Health Problems After Delirium in the ICU. Crit Care Med. 2016;44(10):180813.

85. Morita T, Tei $\mathbf{Y}$, Tsunoda $\mathbf{J}$, Inoue $\mathbf{S}$, Chihara $\mathbf{S}$. Underlying pathologies and their associations with clinical features in terminal delirium of cancer patients. J Pain Symptom Manage. 2001;22(6):9971006.

86. Bush SH, Leonard MM, Agar M, et al. End-of-life delirium: issues regarding recognition, optimal management, and the role of sedation in the dying phase. J Pain Symptom Manage. 2014;48(2):215-30.

87. McLott J, Jurecic J, Hemphill L, Dunn KS. Development of an amygdalocentric neurocircuitry-reactive aggression theoretical model of emergence delirium in posttraumatic stress disorder: an integrative literature review. Aana j. 2013;81(5):379-84.

88. Kelmendi B, Adams TG, Yarnell S, Southwick S, Abdallah CG, Krystal JH. PTSD: from neurobiology to pharmacological treatments. European journal of psychotraumatology. 2016;7:31858.

89. Fitzgerald JM, DiGangi JA, Phan KL. Functional Neuroanatomy of Emotion and Its Regulation in PTSD. Harvard review of psychiatry. 2018 ;26(3):116-28
90. Clausen AN, Francisco AJ, Thelen J, et al. PTSD and cognitive symptoms relate to inhibition-related prefrontal activation and functional connectivity. Depress Anxiety. 2017;34(5):427-36.

91. White SF, Costanzo ME, Thornton LC, Mobley AM, Blair JR, Roy MJ. Increased cognitive control and reduced emotional interference is associated with reduced PTSD symptom severity in a trauma-exposed sample: A preliminary longitudinal study. Psychiatry research Neuroimaging. 2018;278:7-12.

92. Patel MB, Jackson JC, Morandi A, et al. Incidence and Risk Factors for Intensive Care Unit-related Post-traumatic Stress Disorder in Veterans and Civilians. Am J Respir Crit Care Med. 2016;193(12): 1373-81

93. Jackson JC, Pandharipande PP, Girard TD, et al. Depression, posttraumatic stress disorder, and functional disability in survivors of critical illness in the BRAIN-ICU study: a longitudinal cohort study. The Lancet Respiratory medicine. 2014;2(5):369-79.

94. van Loo HM, Romeijn JW. Psychiatric comorbidity: fact or artifact? Theor Med Bioeth. 2015;36(1):41-60.

95. Allsopp K, Read J, Corcoran R, Kinderman P. Heterogeneity in psychiatric diagnostic classification. Psychiatry Research. 2019;279:15-22.

96. Ross LE, Vigod S, Wishart J, et al. Barriers and facilitators to primary care for people with mental health and/or substance use issues: a qualitative study. BMC Fam Pract. 2015;16:135.

97. Henderson C, Evans-Lacko S, Thornicroft G. Mental illness stigma, help seeking, and public health programs. Am J Public Health. 2013; 103(5):777-80.

98. Finley EP, Mader M, Bollinger MJ, et al. Characteristics Associated With Utilization of VA and Non-VA Care Among Iraq and Afghanistan Veterans With Post-Traumatic Stress Disorder. Military medicine. 2017;182(11):e1892-e903.

99. Maynard C, Batten A, Liu CF, Nelson K, Fihn SD. The Burden of Mental Illness Among Veterans: Use of VHA Health Care Services by Those With Service-connected Conditions. Med Care. 2017;55(11):965-

100. Lavin K, Davydow DS, Downey L, et al. Effect of Psychiatric Illness on Acute Care Utilization at End of Life From Serious Medical Illness. J Pain Symptom Manage. 2017;54(2):176-85.e1.

101. McDermott CL, Bansal A, Ramsey SD, Lyman GH, Sullivan SD. Depression and Health Care Utilization at End of Life Among Older Adults With Advanced Non-Small-Cell Lung Cancer. Journal of pain and symptom management. 2018;56(5):699-708. e1.

102. Doan K, Levy B, Gross CP, Wang S-Y. Associations between pre-and post-cancer depression diagnoses and end-of-life cancer care intensity. J Clin Pathways. 2016;2:47-54

103. Temel JS, McCannon J, Greer JA, et al. Aggressiveness of care in prospective cohort of patients with advanced NSCLC. Cancer. 2008; 113(4):826-33.

104. Koss C. Encounters With Health-Care Providers and Advance Directive Completion by Older Adults. J Palliat Care. 2018;33(3):178-81.

105. Rao JK, Anderson LA, Lin FC, Laux JP. Completion of advance directives among U.S. consumers. Am J Prev Med. 2014;46(1):65-70.

106. Gravely AA, Cutting A, Nugent S, Grill J, Carlson K, Spoont M. Validity of PTSD diagnoses in VA administrative data: comparison of VA administrative PTSD diagnoses to self-reported PTSD Checklist scores. J Rehabil Res Dev. 2011;48(1):21-30.

107. Holowka DW, Marx BP, Gates MA, et al. PTSD diagnostic validity in Veterans Affairs electronic records of Iraq and Afghanistan veterans. J Consult Clin Psychol. 2014;82(4):569-79.

Publisher's Note Springer Nature remains neutral with regard to jurisdictional claims in published maps and institutional affiliations. 